\title{
The quantitative genetics of sex allocation in the andromonoecious perennial, Solanum carolinense (L.)
}

\author{
ELIZABETH ELLE* \\ Program in Ecology and Evolution, Rutgers University, New Brunswick, NJ 08903, U.S.A.
}

\begin{abstract}
The quantitative genetics of allocation to sexual functions was examined in the andromonoecious plant, Solanum carolinense. A restricted maximum likelihood (REML) analysis was employed to determine heritabilities and genetic and environmental correlations for flower number, the proportion of those flowers that were male, and the size of flower parts (corolla diameter, pistil length, and anther length and width) in each of three populations used in a diallel crossing design. All floral characters were highly heritable. The sizes of flower parts were positively genetically correlated with one another, which will restrict the independent evolution of these parts. Negative genetic and environmental correlations exist between flower size and proportion male flowers, indicating the potential for the evolution of individuals with either many, small male flowers or few, large, cosexual flowers. The high heritabilities of the traits examined as well as the genetic correlations among them indicate the potential for the evolution of gender specialization in this species, because flower size and number have the potential to affect sex-specific reproductive success.
\end{abstract}

Keywords: breeding systems, genetic correlations, heritability, restricted maximum likelihood, sex allocation, Solanum carolinense.

\section{Introduction}

Breeding system evolution in plants is largely a function of the reproductive gains associated with allocation of limited resources to different sexes within individuals. The need to allocate limited resources to potentially conflicting sex functions will cause trade-offs in cosexual individuals, which express both male and female sexes, and may have been one of the selective forces for the evolution of dioecy, in which separate sexes are expressed in different plants (Charlesworth \& Charlesworth, 1978; Bawa, 1980; Meagher, 1992). Andromonoecy, in which both cosexual and male flowers are present together within individuals, may have evolved in response to similar resource conflicts; the production of extra male flowers may allow continued male reproduction when further fruit production (female reproduction) is unlikely because of resource constraints (Primack \& Lloyd, 1980; Bertin, 1982; Whalen \& Costich, 1986; Solomon, 1987; Diggle, 1991).

\footnotetext{
*Present address: Department of Entomology, University of California-Riverside, Riverside, CA 92521, U.S.A. E-mail: elle@citrus.ucr.edu
}

Cosexual plants rarely have equal reproductive success through male and female functions (Lloyd, 1980; Ross, 1990). Plant gender includes aspects of flower size and flower number, which may differ in their impacts on sex-specific fitness. In plants with more than one flower type, the relative proportion of each morph produced will be an important determinant of the reproductive success gained through each sex. In andromonoecious species, excess male flower production may increase attractiveness of a plant to pollinators, thereby increasing male success (Bertin, 1982; Whalen \& Costich, 1986; Devlin et al., 1992). Allocation of resources to different flower parts may also affect sex-specific success. For example, large petals or other attractive structures may primarily increase male, but not female, success (Bell, 1985; Young \& Stanton, 1990; Campbell et al., 1991). Variation in sex allocation can therefore lead to phenotypically mediated variation in sex-specific success, potentially leading to gender specialization. Only if variation among individuals in flower size or number has a genetic basis, can the tendency for gender specialization be passed on to offspring (e.g. Robertson et al., 1994). The potential for the evolu- 
tion of sex allocation patterns and resulting breeding systems can therefore best be examined through the use of quantitative genetic analysis tools (Morgan, 1992, 1994).

Variation in whole-plant characters such as flower number is often expected to be largely a function of environmental conditions (Anderson, 1979; Primack \& Lloyd, 1980; Houle, 1992), and so may be relatively impervious to selection. Variation in sizes of floral parts or other within-module characters is more likely to have a genetic basis, but these characters may not be able to evolve independently of one another. If resources are limited, allocation tradeoffs are likely between different sex functions, which may lead to negative genetic correlations among reproductive traits (Atlan et al., 1992; Mazer \& Hultgård, 1993). Alternatively, developmental constraints and other factors often lead to positive genetic correlations among floral characters, which have been documented frequently (deLaguerie et al., 1991; O’Neill \& Schmitt, 1993; Fenster \& Ritland, 1994; Meagher, 1994; Stanton \& Young, 1994; Ågren \& Schemske, 1995). In either case, significant genetic correlations among floral characters will limit independent evolution of sex-specific phenotypic traits (Dorn \& Mitchell-Olds, 1991). This may specifically be an issue in the family Solanaceae, in which floral morphology is highly conserved (see for example Harder \& Barclay, 1994; King \& Buchman, 1996). It is therefore necessary to measure the genetic correlations among floral characters, as well as the amount of underlying genetic variance, to determine whether the independent evolution of sex-specific reproductive characters is possible (e.g. Stanton \& Young, 1994; Meagher, 1994).

This paper explores the genetic basis of sex allocation in an andromonoecious plant, Solanum carolinense (L.) (Solanaceae). I make use of a crossgenerational quantitative genetic analysis to address the following specific questions. (i) Are flower number, flower morph ratio, and flower size heritable characters in $S$. carolinense? (ii) What are the genetic and environmental correlations among floral characters? (iii) How might these characteristics aid or constrain the evolution of gender specialization in this species?

\section{Methods}

The study species

Solanum carolinense, horsenettle, is a native perennial pasture weed common throughout much of the United States. The species is weakly andromonoe- cious, with the potential to bear both cosexual and male flowers on an inflorescence, although cosexual flowers tend to be more numerous (Whalen \& Costich, 1986). The two flower types are perfect and quite similar, but male flowers are smaller overall (see below), have greatly reduced pistils, and are incapable of setting fruit (Solomon, 1986). Cosexual flowers are produced basally, and the male flowers (when present) at the tips of inflorescences. There is no nectar, and the showy anthers are attractive to pollinators, for whom pollen is the only reward (Solomon, 1987). The fruit is a berry, ripening to bright yellow, and containing an average of 160 seeds (E. Elle, unpubl. data). Individuals are selfincompatible under typical field conditions, so all seeds produced are through outcrossing, although the incompatibility system may break down under greenhouse conditions (A. Stephenson, pers. comm.; E. Elle, pers. obs.).

\section{Crossing design}

Genetic analyses were conducted for each of three populations. Ripe fruits were collected from: (i) a sheep pasture at Cook College, Rutgers University, New Brunswick, NJ; (ii) Brookfield landfill (closed) on Staten Island, NY; and (iii) an old field at Hutcheson Memorial Forest, Franklin Township, NJ. Fruits were collected from 12 source plants in each population. Because plants are capable of clonal spread, source plants were spatially isolated from one another (at least $2 \mathrm{~m}$ apart), with the intention of increasing the probability that they were genetically distinct individuals.

Seedlings from each source plant family with adequate germination (Sheep Pasture: eight families; Landfill and Old Field: 10 families) were reared in the greenhouse at Rutgers University, Piscataway, NJ, and one plant from each source plant family was randomly chosen to use in crosses. Crosses were performed on greenhouse-reared plants to minimize the environmental variance experienced by the parent generation and resultant maternal effects, and to produce a family structure (including full-sibs nested within paternal half-sib families) appropriate for a genetic analysis. Plants were randomized within the greenhouse, and each plant chosen for crosses was used as both pollen donor and pollen recipient in crosses with individuals from other families within that population. All possible crosses within populations were performed twice. The design therefore included all reciprocal crosses, and two replicates of each cross.

(C) The Genetical Society of Great Britain, Heredity, 80, 481-488. 
Some crosses were unsuccessful, most likely because of the compatibility relationships among the plants.

All flowers used in crosses were bagged prior to anthesis, to prevent accidental pollination. Fruit-set was common in unbagged flowers, and along with declining day length led to natural senescence of the plants. Therefore, crosses were performed in two temporal blocks. The first block was performed under natural light conditions in the greenhouse. After fruits from these crosses were collected, plants were cut back and placed under lights simulating $16 \mathrm{~h}$ days. This lighting regime allowed completion of the crosses by ensuring continued flowering of the plants. Crosses were not evenly distributed among blocks, because of natural variation among individuals in flowering frequency. Block effects are included in genetic analyses to control for variation in lighting and other environmental effects, and subsequent effects on floral characters (see below).

Seeds from one of the replicate fruits for each successful cross (including reciprocal crosses) were used to produce the offspring generation. Replicate fruits and seeds were chosen in a haphazard manner. A total of 1055 plants representing 28 paternal half-sibships were grown in completely randomized positions within the greenhouse. Both the offspring generation and the first temporal block of the initial (parent) generation were raised in the same greenhouse, during the same time of year (in two subsequent years), under natural light. The generations differed primarily in pot size; parent plants were raised in five-inch pots, and offspring in three-inch pots because of space constraints. To account for environmental differences between different areas in the greenhouse, as well as among years, a bench effect was included in the genetic analysis (see below).

\section{Phenotypic measurements}

Floral characters were measured on each of the parent and offspring plants used in this study. The total number of flowers produced before natural senescence, and the proportion of those flowers that were male, were counted for each individual. These estimates of whole-plant allocation to reproduction were chosen because total flower number may be an important signal to pollinators (Bertin, 1982; Devlin et al., 1992), and the proportion of male flowers produced provides an estimate of the gender potential of an individual (Primack \& Lloyd, 1980; Bertin, 1982). In addition, flower size was determined by measuring corolla diameter, pistil length, and anther length and width for four cosexual flowers (three in the offspring generation) on each plant and up to four male flowers, dependent upon male flower production. Only cosexual flowers were used to estimate flower size in genetic analyses (see below) because male flower production was very uneven among individuals, and sample sizes were therefore very low. Means for flower size were calculated by individual for use in the analysis. When plants did not flower, or if their flowers were not measured, they were not included in the analysis of flower size, but were included in the analysis of flower number, because the lack of flower production is a valid allocation strategy in this perennial, vegetatively reproducing plant. The number of individual plants in each generation, and the number of those individuals that flowered, is indicated in Table 1.

\section{Analyses}

Each population was analysed separately. My goal was to determine the additive genetic variance/heritability for each trait, as well as the genetic correlation structure among traits. The presence of additive genetic variance indicates the potential for the evolution of a trait, whereas genetic correlations among traits indicate that independent evolution of the traits will be constrained by their relationship to one another (Falconer, 1989). The two-generation design described above includes parent/offspring, full-sib, and half-sib relationships, all of which contribute information to the analysis. To take full advantage of this information, I employed a restricted maximum likelihood approach (REML) to estimate heritabilities and correlations. In addition to its power for use with extended pedigrees, REML is preferred to ANOVA for statistically unbalanced data (Shaw, 1987). The data from the current study are unbalanced because of variation in the success of crosses, most likely caused by the compatibility relationships among plants, and natural variation in survivorship and flowering of the offspring generation. The REML approach, unlike other methods for estimating heritability, allows highly accurate estimation of effects, especially from nontraditional or unbalanced crossing designs (see Falconer, 1989 for a discussion of the difficulties in obtaining precise heritability estimates).

For this analysis, I used the PEST/VCE REML package by Neumaier \& Groeneveld (in press; ftp site 192.108.34.1). This program estimated the heritabilities and genetic and environmental correlations for the traits I measured, incorporating pedigree data from the entire data set. Also determined were the variances associated with these maximum likeli- 
Table 1 Means for floral traits for each of two generations in a crossing design, for each of three source populations of Solanum carolinense. Variable names in bold were used in the quantitative genetic analysis, for which means were calculated by individual. Sample sizes: total number of plants in generation/number of plants that flowered/total cosexual flowers measured/total male flowers measured

\begin{tabular}{|c|c|c|c|c|c|c|c|c|c|c|c|c|}
\hline \multirow{3}{*}{ Sample size } & \multicolumn{4}{|c|}{ Sheep Pasture } & \multicolumn{4}{|c|}{ Landfill } & \multicolumn{4}{|c|}{ Old Field } \\
\hline & \multicolumn{2}{|c|}{$\begin{array}{l}\text { Parents } \\
8 / 8 / 32 / 26\end{array}$} & \multicolumn{2}{|c|}{$\begin{array}{c}\text { Offspring } \\
217 / 129 / 196 / 50\end{array}$} & \multicolumn{2}{|c|}{$\begin{array}{c}\text { Parents } \\
10 / 10 / 40 / 13\end{array}$} & \multicolumn{2}{|c|}{$\begin{array}{c}\text { Offspring } \\
382 / 276 / 486 / 81\end{array}$} & \multicolumn{2}{|c|}{$\begin{array}{c}\text { Parents } \\
10 / 10 / 40 / 22\end{array}$} & \multicolumn{2}{|c|}{$\begin{array}{c}\text { Offspring } \\
407 / 201 / 269 / 65\end{array}$} \\
\hline & Mean & SD & Mean & $\mathrm{SD}$ & Mean & SD & Mean & SD & Mean & SD & Mean & $\mathrm{SD}$ \\
\hline \multicolumn{13}{|l|}{ Overall flowers } \\
\hline Flower number & 12.25 & 10.49 & 4.74 & 5.57 & 36.00 & 14.33 & 6.98 & 7.09 & 18.60 & 16.54 & 4.23 & 5.97 \\
\hline Proportion male & 0.15 & 0.18 & 0.07 & 0.19 & 0.15 & 0.17 & 0.03 & 0.13 & 0.15 & 0.16 & 0.03 & 0.11 \\
\hline \multicolumn{13}{|l|}{ Cosexual flowers } \\
\hline Corolla diameter & 31.09 & 3.40 & 32.38 & 4.45 & 29.54 & 2.94 & 29.70 & 3.41 & 32.25 & 3.20 & 31.23 & 4.20 \\
\hline Pistil length & 11.99 & 1.65 & 12.40 & 1.41 & 11.23 & 1.23 & 11.32 & 1.32 & 11.45 & 1.13 & 11.84 & 1.42 \\
\hline Anther length & 7.71 & 0.59 & 7.72 & 0.74 & 7.48 & 0.54 & 6.97 & 0.74 & 8.82 & 0.84 & 8.25 & 1.05 \\
\hline Anther width & 2.15 & 0.16 & 2.15 & 0.21 & 2.23 & 0.82 & 2.11 & 0.38 & 2.00 & 0.21 & 2.01 & 0.36 \\
\hline \multicolumn{13}{|l|}{ Male flowers } \\
\hline Corolla diameter & 26.64 & 3.58 & 30.12 & 4.25 & 22.84 & 2.77 & 26.80 & 3.30 & 26.14 & 3.79 & 29.40 & 3.26 \\
\hline Pistil length & 3.50 & 1.05 & 2.62 & 1.18 & 2.79 & 0.70 & 3.02 & 1.34 & 2.60 & 1.16 & 2.33 & 1.00 \\
\hline Anther length & 6.95 & 0.72 & 7.31 & 1.09 & 6.62 & 0.63 & 6.82 & 0.79 & 7.79 & 0.85 & 7.79 & 0.92 \\
\hline Anther width & 1.97 & 0.18 & 2.02 & 0.23 & 1.98 & 0.14 & 2.07 & 0.18 & 1.84 & 0.18 & 1.97 & 0.66 \\
\hline
\end{tabular}

hood estimates, which allowed me to determine their significance through the use of $t$-tests. This is a powerful method of determining the precision of heritability estimates, because correlations that are small in magnitude can be determined to be significantly different from zero if their variances are also correspondingly small. The REML model included pedigree effects to estimate genetic variance components, and factored out fixed effects of block (time of cross) and bench (location in the greenhouse), because these environmental factors contributed to the phenotypic variation exhibited by the plants. Parent plants were assigned a different block and bench designation to account for differences between the generations in environmental factors.

\section{Results}

Means for all traits by source population for both the parent and offspring generations are presented in Table 1. The three source populations differed for all aspects of flower size and number, with the population having the highest mean flower number (Landfill) producing the smallest flowers. Male flowers were smaller than cosexual flowers, and there was a trend for flower parts, especially the corolla, to be larger in the offspring generation than the parent generation. Flower number varied greatly between generations and among populations, as well as among individuals (note the high standard deviation), as did the proportion of male flowers produced. Many individuals in the offspring generation did not flower, whereas parent plants (which lived longer and grew larger) produced many more flowers overall. Size differences between generations were largely caused by the smaller pot size required for growing larger numbers of plants in the offspring generation.

Most traits measured were heritable in all three experimental populations, with the exception of flower number and proportion male in the Sheep Pasture population (Table 2). Flower size variables exhibited especially high heritabilities, averaging around 0.40 but ranging as high as 0.78 for anther length in the Sheep Pasture population. The proportion of male flowers produced was also a highly heritable trait in two populations. Heritability for flower number ranged from 0.16-0.19, lower than the other heritabilities calculated in this experiment.

Flower size variables were positively genetically correlated with one another, especially in the Landfill and Old Field source populations (Table 2); in all populations, flower size variables also exhibited positive environmental correlations. This means that any change in the size of one flower part will be accompanied by a similar change in the size of other 
flower parts, and that the environment tends to affect all flower size variables similarly.

Although in all populations there were significant positive environmental correlations between flower number and the proportion male flowers produced, the genetic correlation between these two characters was significant only in the Old Field population. This correlation of 0.31 was the only genetic correlation of large magnitude discerned between flower size and number. Proportion male was negatively environmentally correlated with all flower size vari- ables in all populations, except for anther width, with which it was significantly positively correlated. Again, only in the Old Field population were any of the genetic correlations significant; in this case, small negative correlations between proportion male and corolla diameter and pistil length. Interestingly, these two flower size variables were positively genetically correlated with flower number in the Landfill population, in which there was no genetic correlation between flower number and the proportion of male flowers produced.

Table 2 Heritabilities (bold; diagonal), genetic correlations (upper off-diagonal), and environmental correlations (lower off-diagonal) for floral traits of plants from three source populations of Solanum carolinense

Table 2a Sheep Pasture

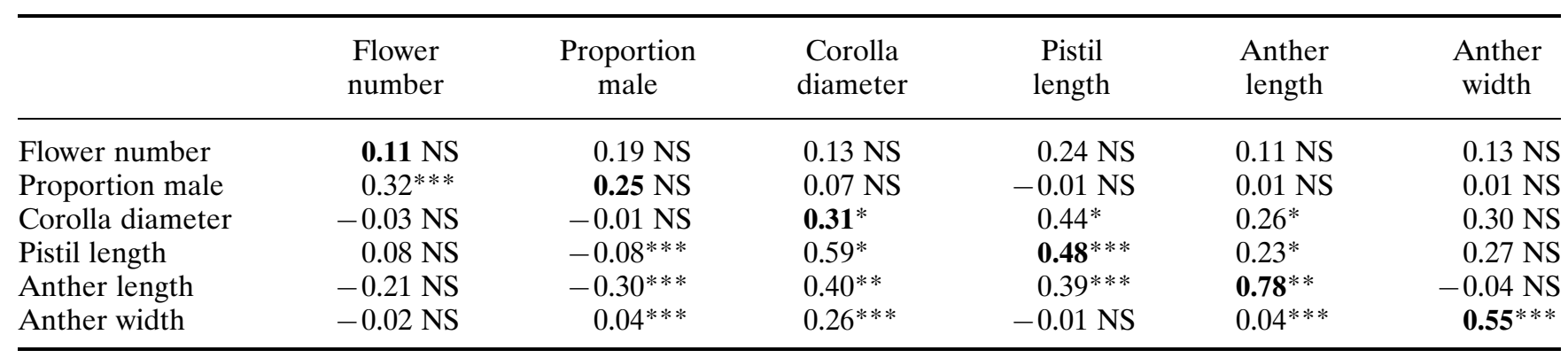

Table 2b Landfill

\begin{tabular}{|c|c|c|c|c|c|c|}
\hline & $\begin{array}{l}\text { Flower } \\
\text { number }\end{array}$ & $\begin{array}{l}\text { Proportion } \\
\text { male }\end{array}$ & $\begin{array}{l}\text { Corolla } \\
\text { diameter }\end{array}$ & $\begin{array}{l}\text { Pistil } \\
\text { length }\end{array}$ & $\begin{array}{l}\text { Anther } \\
\text { length }\end{array}$ & $\begin{array}{l}\text { Anther } \\
\text { width }\end{array}$ \\
\hline Flower number & $\mathbf{0 . 1 9} * * *$ & $0.05 \mathrm{NS}$ & $0.09^{*}$ & $0.10 *$ & $0.06 \mathrm{NS}$ & $0.02 \mathrm{NS}$ \\
\hline Proportion male & $0.08 * * *$ & $0.42 * * *$ & $-0.05 \mathrm{NS}$ & $-0.02 \mathrm{NS}$ & $0.01 \mathrm{NS}$ & $-0.03 \mathrm{NS}$ \\
\hline Corolla diameter & $0.18 \mathrm{NS}$ & $-0.13 * * *$ & $\mathbf{0 . 3 7} * * *$ & $0.33^{* * *}$ & $0.31 * * *$ & $0.10^{*}$ \\
\hline Pistil length & $0.19 \mathrm{NS}$ & $-0.06^{* * *}$ & $0.65 * * *$ & $\mathbf{0 . 4 3} * * *$ & $0.22 * * *$ & $0.08 P<0.1$ \\
\hline
\end{tabular}

Table 2c Old Field

\begin{tabular}{|c|c|c|c|c|c|c|}
\hline Proportion male & $0.28 * * *$ & $0.28 * * *$ & $-0.10^{*}$ & $-0.12^{* *}$ & $-0.02 \mathrm{NS}$ & $-0.02 \mathrm{NS}$ \\
\hline Corolla diameter & $0.02 \mathrm{NS}$ & $-0.20 * * *$ & $0.45 * * *$ & $0.37 * * *$ & $0.33^{*}$ & $0.16^{* * *}$ \\
\hline Pistil length & $0.02 \mathrm{NS}$ & $-0.18^{* * *}$ & $0.59 * * *$ & $0.44^{* * *}$ & $0.34 * * *$ & $0.16^{* * *}$ \\
\hline
\end{tabular}

Asterisks indicate significance level for differences from zero for one-tailed $t$-tests (heritabilities) and two-tailed $t$-tests (correlations): ${ }^{*} P<0.05 ;{ }^{*} P<0.005 ;{ }^{*} * P<0.0001$; NS, not significant. Significance levels for environmental correlations were determined using standard errors for environmental covariances. Sample sizes include total parent and offspring plants upon which measurements were taken for that population: for whole plant traits (flower number and proportion male): Sheep Pasture 225, Landfill 392, Old Field 417; for flower size characters: Sheep Pasture 89, Landfill 204, Old Field 128.

(c) The Genetical Society of Great Britain, Heredity, 80, 481-488. 


\section{Discussion}

This study has shown that flower size and number are heritable characters in Solanum carolinense, although the independent evolution of floral characters may be impeded as a result of significant genetic correlations among them. However, heritability of flower size and the proportion of male flowers produced indicates the potential for the evolution of gender specialization in this species.

In all three populations of $S$. carolinense studied, size of all flower parts measured was highly heritable, indicating the potential for a response to selection on flower size. Large flowers are considered to be highly attractive to pollinators, so flower size is likely to be an important component of reproductive success (Bell, 1985; Young \& Stanton, 1990; Campbell et al., 1991). Also important to reproductive success is the size of the floral display (Bertin, 1982; Devlin et al., 1992); in the Landfill and Old Field populations, flower number and proportion male had significant heritabilities as well. The presence of additive genetic variation for flower production is important because flower number is thought to respond primarily to environmental conditions (Anderson, 1979; Primack \& Lloyd, 1980), which may explain why heritabilities for total flower number are lower than for other traits measured.

The proportion of male flowers produced might, by the same reasoning, be expected to have low heritability; however, this character was highly heritable for both the Landfill and Old Field populations. This may be because many plants did not produce any male flowers at all, and so male flower production may be inherited in a fashion similar to discrete characters, with the presence or absence of male flowers more important than their relative number. This pattern of inheritance would result in some individuals producing both cosexual and male flowers, and others producing cosexual flowers alone. Genetic factors have been shown to control the allocation of resources to male vs. female flowers in cucurbits (Charnov, 1982). However, a study of Solanum hirtum indicated that production of male flowers is a plastic response to resource conditions in this andromonoecious species (Diggle, 1991). In S. carolinense, male flowers are produced after the cosexual flowers, and may be present as a way to ensure further reproduction as a male when fruit production is constrained by resource availability (Primack \& Lloyd, 1980; Bertin, 1982; Whalen \& Costich, 1986; Solomon, 1987; Diggle, 1991). Although the reproductive strategy involving male flower production may be plastic in the Solana- ceae, it appears to be employed only in some of the families of $S$. carolinense included in the current study, which indicates a genetic component that has obvious implications for the evolution and maintenance of andromonoecy in this species.

Although flower size and number could respond to selection in $S$. carolinense, any evolution of the breeding system will be constrained by the relationships among the floral traits in question. Flower shape, for example, may resist selection for change in this species, because the sizes of flower parts are genetically correlated with one another. Positive genetic correlations have been found among sizes of flower parts in several plant species (deLaguerie et al., 1991; O’Neill \& Schmitt, 1993; Carr \& Fenster, 1994; Meagher, 1994; Stanton \& Young, 1994; Ågren \& Schemske, 1995), indicating constraints on the evolution of floral form. On the other hand, the genetic correlation structure between flower number, proportion male, and flower size may be important in its effect on the evolution of gender specialization. There were few significant genetic correlations detected by this study; but those that exist indicate the potential for the evolution of plants with many, small, male flowers as opposed to few, large, cosexual flowers.

\section{Implications for breeding system evolution}

This study has shown that genetic variation exists for floral characters in $S$. carolinense. Especially significant is: (i) the high heritability of the proportion of male flowers produced, because this has the potential to affect the gender expression of individuals; (ii) the presence in at least one population of negative genetic correlations between proportion male and flower size; and (iii) a positive genetic correlation between proportion male and flower number. This may indicate the potential for the evolution of functionally male plants with many, small, male flowers, and functionally female plants with few, large, cosexual flowers.

The Solanaceae, and especially the genus Solanum, includes species expressing a diversity of breeding systems (Anderson, 1979). Cosexual taxa include true hermaphrodites, where each flower is cosexual, as well as a range of expression of andromonoecy (Anderson, 1979; Whalen \& Costich, 1986). Also present in the genus are several functionally dioecious species (formerly classified as androdioecious). In these species, individuals produce either male flowers or cosexual flowers, but morphologically cosexual flowers (and plants) can achieve reproductive success only through female 
function (Anderson, 1979; Anderson \& Symon, 1989). Anthers on these plants produce nonfunctional pollen, and may be retained because of the role of anthers in attracting pollinators (Solomon, 1987; Anderson \& Symon, 1989; Harder \& Barclay, 1994) which is necessary to ensure fruit set.

The heritable variation observed in $S$. carolinense in the current study for both flower size and the proportion of male flowers produced may be an important factor leading to the evolution of a breeding system like functional dioecy. This is especially relevant if genetic variation is coupled with sex-specific, phenotypically determined variation in relative fitness (Morgan, 1992, 1994). Field experiments designed to measure the sex-specific fitness effects of allocation to different floral parts and flower types in $S$. carolinense indicate that large flower size may be more important to male than female success, and that increased male flower production increases male success and decreases female success (E. Elle, in prep.). Heritable variation among plants in their floral characters therefore leads to differences among them in functional gender, which has important implications for breeding system evolution in this species.

\section{Acknow ledgements}

The author thanks T. Meagher, S. Kaufman, P. McMillan, P. Smouse, A. Snow, J. Wilcox, and two anonymous reviewers for comments that greatly improved this manuscript. Discussions with R. Shaw increased my understanding of the benefits of REML, and the patient help of T. Meagher was invaluable to the analysis. Thanks also to the folks at Edinburgh University for useful discussion, especially S. Brotherstone for her recommendation of the PEST/ vCE package. This research was supported by an NSF Doctoral Dissertation Improvement Grant (DEB-9411513).

\section{References}

ÅgREN, J. AND SCHEMSKE, D. W. 1995. Sex allocation in the monoecious herb Begonia semiovata. Evolution, 49, 121-130.

ANDERson, G. J. 1979. Dioecious Solanum species of hermaphroditic origin is an example of a broad convergence. Nature, 282, 836-838.

ANDERSON, G. J. AND SYMON, D. E. 1989. Functional dioecy and andromonoecy in Solanum. Evolution, 43, 204-219.

ATLAN, A., GOUYON, P.-H., FOURNIAL, T., POMENTE, D. AND COUVET, D. 1992. Sex allocation in an hermaphroditic plant: the case of gynodioecy in Thymus vulgaris L. J. Evol. Biol., 5, 189-203.
BAWA, K. s. 1980. Evolution of dioecy in flowering plants. Ann. Rev. Ecol. Syst., 11, 15-39.

BELL, G. 1985. On the function of flowers. Proc. R. Soc. B., 224, 223-265.

BERTIN, R. I. 1982. The evolution and maintenance of andromonoecy. Evol. Theory, 6, 25-32.

CAMPBEll, D. R., WASER, N. R., PRICE, M. V., LYNCH, E. A. AND MITCHELl, R. J. 1991. Components of phenotypic selection: pollen export and flower corolla width in Ipomopsis aggregata. Evolution, 45, 1458-1467.

CARR, D. E. AND FENSTER, C. B. 1994. Levels of genetic variation and covariation for Mimulus (Scrophulariaceae) floral traits. Heredity, 72, 606-618.

CHARLESWORTH, B. AND CHARLESWORTH, D. 1978. A model for the evolution of dioecy and gynodioecy. Am. Nat., 112, 975-997.

Charnov, E. L. 1982. The Theory of Sex Allocation. Princeton University Press, Princeton, NJ.

Delaguerie, P., Olivieri, I., ATlAN, A. AND GOUYON, P.-H. 1991. Analytic and simulation models predicting positive genetic correlations between traits linked by tradeoffs. Evol. Ecol., 5, 361-369.

DeVlin, B. I., ClegG, J. AND Ellstrand, N. C. 1992. The effect of flower production on male reproductive success in wild radish populations. Evolution, 46, 1030-1042.

DIGGLE, P. K. 1991. Labile sex expression in andromonoecious Solanum hirtum: pattern of variation in floral structure. Can. J. Bot., 69, 2033-2043.

DORN, L. A. AND MITCHELL-OLDS, T. 1991. Genetics of Brassica campestris. I. Genetic constraints on evolution of life-history characters. Evolution, 45, 371-379.

FALCONER, D. S. 1989. Introduction to Quantitative Genetics, 3rd edn. John Wiley and Sons, New York.

FENSTER, C. B. AND RITLAND, K. 1994. Quantitative genetics of mating system divergence in the yellow monkeyflower species complex. Heredity, 73, 422-435.

HARDER, L. D. AND BARCLAY, R. M. R. 1994. The functional significance of poricidal anthers and buzz pollination: controlled pollen removal from Dodecatheon. Funct. Ecol., 8, 509-517.

HOULE, D. 1992. Comparing evolvability and variability of quantitative traits. Genetics, 130, 195-204.

KING, M. J. AND BUCHMANN, s. L. 1996. Sonication dispensing of pollen from Solanum laciniatum flowers. Funct. Ecol., 10, 449-456.

LlOYD, D. G. 1980. Sexual strategies in plants III. A quantitative method for describing the gender of plants. $N$. Z. J. Bot., 18, 103-108.

MAZER, S. J. AND HULTGÅRD, U.-M. 1993. Variation and covariation among floral traits within and among four species of northern European Primula (Primulaceae). Am. J. Bot., 80, 474-485.

MEAGHER, T. R. 1992. The quantitative genetics of sexual dimorphism in Silene latifolia (Caryophyllaceae). I. Genetic variation. Evolution, 46, 445-457.

MEAGHER, T. R. 1994. The quantitative genetics of sexual dimorphism in Silene latifolia (Caryophyllaceae). II. 
Response to sex-specific selection. Evolution, 48, 939-951.

MORGAN, M. T. 1992. The evolution of traits influencing male and female fertility in outcrossing plants. Am. Nat., 139, 1022-1051.

MORGAN, M. T. 1994. Models of sexual selection in hermaphrodites, especially plants. Am. Nat., 144, S100-S125.

NEUMAIER, A. AND GROENEVELD, E. (in press). Restricted maximum likelihood estimation of covariances in sparse linear models. Génét. Sél. Évol.

O'NEILL, P. AND SCHMITT, J. 1993. Genetic constraints on the independent evolution of male and female reproductive characters in the tristylous plant Lythrum salicaria. Evolution, 47, 1457-1471.

PRIMACK, R. B. AND LlOYD, D. G. 1980. Andromonoecy in the New Zealand montane shrub Manuka, Leptospermum scoparium (Myrtaceae). Am. J. Bot., 67, 361-368.

ROBERTSON, A. w. 1994. The quantitative genetics of floral characters in Mimulus guttatus. Heredity, 72, 300-311.

Ross, M. D. 1990. Sexual asymmetry in hermaphroditic plants. Trends Ecol. Evol., 5, 43-47.

SHAw, R. G. 1987. Maximum-likelihood approaches to quantitative genetics of natural populations. Evolution, 41, 812-826.

SOlOMON, B. P. 1986. Sexual allocation and andromonoecy: resource investment in male and hermaphrodite flowers of Solanum carolinense (Solanaceae). Am. J. Bot., 73, 1215-1221.

Solomon, B. P. 1987. The role of male flowers in Solanum carolinense: pollen donor or pollinator attractors? Evol. Trends Plants, 1, 89-93.

STANTON, M. L. AND YOUNG, H. J. 1994. Selecting for floral character associations in wild radish, Raphanus sativus L. J. Evol. Biol., 7, 271-285.

whalen, M. D. AND Costich, D. E. 1986. Andromonoecy in Solanum. In: D'Arcy, W. G. (ed.) Solanaceae Biology and Systematics, pp. 284-302. Columbia University Press, New York.

YOUNG, H. J. AND STANTON, M. L. 1990. Influence of environmental quality on pollen competitive ability in wild radish. Science, 248, 1631-1633. 